\title{
Inquiry Learning Evaluation System Under the Environment of Cyber Learning Space
}

\author{
Liu Hong ${ }^{1}$, Wang $\mathrm{Li}^{2}$, Li Dawei ${ }^{1,}$ * \\ ${ }^{1}$ School of Science, University of Science and Technology Liaoning, Anshan, China \\ ${ }^{2}$ School of Electronics and Information Science, University of Science and Technology Liaoning, Anshan, China \\ Email address: \\ ldhliuhong@163.com (Liu Hong),wangli@ustl.edu.cn (Wang Li), lidawei@ustl.edu.cn (Li Dawei) \\ ${ }^{*}$ Corresponding author
}

\section{To cite this article:}

Liu Hong, Wang Li, Li Dawei. Inquiry Learning Evaluation System Under the Environment of Cyber Learning Space. Humanities and Social Sciences. Vol. 4, No. 2, 2016, pp. 42-45. doi: 10.11648/j.hss.20160402.14

Received: April 1, 2016; Accepted: April 8, 2016; Published: April 14, 2016

\begin{abstract}
As an innovation mechanism of integration of information technology and education, cyber learning space is a basic platform for teaching activities and teaching management under the condition of information technology. It is a new task how to make a scientific, rational, objective and fair comprehensive evaluation of the students' autonomous learning activities, under this kind of background. In this paper, the goal and the route of learning evaluation system under the environment of cyber learning space is explored, the learning evaluation principle, evaluation function, evaluation method and evaluation index are clear and definite, a set of data acquisition, analysis and processing methods for students learning are established, as well as the perfect index system evaluation model. These research results have been gradually applied in the teaching practice.
\end{abstract}

Keywords: Cyber Learning Space, Teaching Activities, Learning Evaluation, Index System

\section{Introduction}

Cyberspace, also known as the virtual space, the first appeared in the American science fiction writer William Gibson's novel "Neuromancer", refers to the electronic equipment access human neural network after the dreamland [1]. The cyberspace early was considered a science term, and often appeared in the science fiction or movies. Cyberspace has created a new mode of interpersonal communication, and the structure of a realistic existence, profoundly influenced the construction of the modern life world. Especially, cyberspace impacts deeply on youth's way of life, the way of access to information, the way of knowledge acquisition, and so on. For example, an investigation made by the Pew Research Center for teenagers from 13 to 17 in USA found that $92 \%$ of teenagers surf the internet at least once a day. Some social medias like Facebook, Instagram, and Snapchat, have become the most commonly communication tool for teenagers [2]. By the China's Communist Youth League, jointly issued the China campus weibo development report (2015) showed that until the end of June 2015, Sina weibo users of teenagers had more than 52 million [3].
Thus, the application of the network of social media is very popular for teenagers, communication and collaboration in cyberspace becomes more and more important to their lifestyle and communication way.

Also called cyber learning space in the field of education, the cyberspace is a kind of virtual learning environment based on the internet [4].

Cyber learning space is to improve the quality of teachers and the quality of teaching, which is a social platform for serving teachers, students and their parents. It provides the support for teachers to carry out teaching and research activities on the cyberspace or virtual space, and also for the interactions between the teachers and the students.

Cyber learning space also improves the teachers' abilities of information technology application with high quality resource capabilities. School space agencies can manage all the teachers and students' space, and make statistics the frequencies and effect of teaching activities on the internet, the activities of online teaching, the information technology application level and students' learning can be also evaluated.

Nowadays, there are many different types of cyber learning systems, such as MOOC, WeChat and so on, a learning space 
cloud service model is built between teachers and students based on the cyberspace, to provide convenience for the students' autonomous learning and sharing teaching resources, the interactions, knowledge management, teaching management and other functions between teachers and students can be realized, it also can customize various types of cyber learning space services for users. It completely changes the traditional concepts of education, which means "Student is the education object, teacher is the subject" changes to "Student is the education subject, and the teacher is the object".

As a feedback regulation mechanism, learning evaluation plays an important role in the process of learning and teaching, and also one of the key research object education experts and psychologists. Learning evaluation has some functions, like diagnosis function, adjustment function, motivation function and guidance function. In a word, learning evaluation itself is a kind of learning activity, it is the indispensable an important part of the learning process.

In 2014, California of the United States issued a Common Core State Standards (CCSS). Based on CCSS, California Assessment of Student Performance and Progress (CAASPP) designed a students learning evaluation system, which purpose was to improve student learning, and provide useful feedback information for teachers and students [5].

Based on internet information technology teaching and learning environment, it provides the knowledge management and independent learning platform for individual students, and also provides the teaching management and assessment services for educational administrative units and departments $[6,7]$. Under this background, how to make a scientific, reasonable, objective and fair evaluation for students' autonomous learning activities becomes a brand-new topic and new challenges. So the study about learning evaluation under the environment of cyber learning space has great significance.

\section{Establishment of Learning Evaluation System under Cyber Learning Space}

\subsection{Evaluation Methods Under Traditional Teaching Mode}

Over the years, the classroom teaching has been the teaching mode in universities in China, the traditional teaching mode can be summarized as "with the teacher as the center, the classroom as the center, teaching materials as the center" $[8,9]$. It becomes a fixed thinking mode for teaching managers and university teachers. Although classroom teaching is good for emotional exchange between teachers and students, teachers' classroom control, and mobilizing students learning enthusiasm and other advantages, there are also many problems, such as single, low efficiency, passive learning. For learning activities of students, it is usually through classroom questioning, tutoring to understand and grasp the students' situations, the comprehensive performance of students learning is evaluated according to the daily performance and course examination.
This evaluation method has certain rationality and convenient operation, however, it completely ignores the learn status of contemporary college students, such as classroom questioning can not take care of everyone, tutor and students may because there are other classes or community activities and can not participate in the questions and answers, homework has large plagiarism and teachers is unable to stop, it is difficult to make timely, scientific and reasonable evaluation. Therefore, it is urgent to improve the learning evaluation method under the cyberspace.

\subsection{Objective Creation of Learning Evaluation System Under Cyberspace Support}

Under the cyber learning space support, using the internet and data mining technology, the tracking and monitoring of students' learning activities is carried out under the network environment to obtain all students' data in each learning link, the evaluation indicators and evaluation system of the students' autonomous learning activities are established based on cyber learning space.

By using the obtained data and according to the established model, a comprehensive, objective, scientific and fair evaluation is given for the learning activities of students, teaching management departments can understand and grasp the learning situation of the students and the knowledge acceptance to provide a scientific basis, it can promote the autonomous learning initiative and enthusiasm, and improve the efficiency of learning. According to each student's learning background, foundation, expertise, and learning characteristics, the lectures time is optimized to customize the personalized learning program, which will train qualified service personnel for the requirement of the development of the era.

\subsection{Route of Learning Evaluation System Under Cyberspace Support}

The learning mode of cyber learning space is a subversion of the traditional teaching mode, and it is a new challenge to the evaluation of the new teaching mode. One of the differences between the new teaching mode and the traditional one is that although the teachers do not need to communicate with the students by face to face, they can use real time recording the students' learning process, learning condition and learning results. By processing of the recorded data, tracking the status of students can be tracked, and timely feedback is given to the students. Of course it also can make full use of the learning space for online real-time guidance.

Based on the differences between the learning evaluation in the analysis and comparison of traditional teaching mode and cyber learning space support, the characteristics of new learning evaluation are extracted. According to the characteristics, the learning evaluation principles and functions are given, the evaluation indexes are proposed, and learning evaluation model is built based on the technology of the internet technology and data mining technology.

The whole process can be described by seven steps, see figure 1 . 


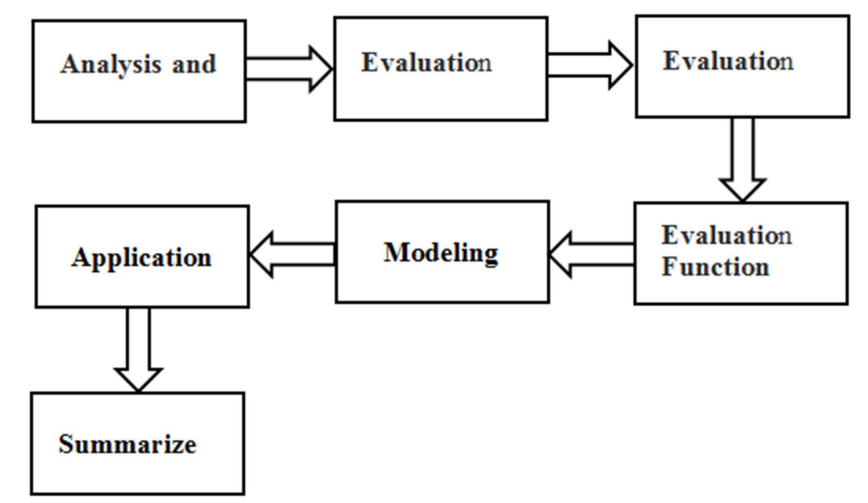

Figure 1. Roadmap of constructing the learning evaluation system under the cyber learning space.

\section{Construction of Learning Evaluation System Under Cyber Space Support}

There are three layers of meanings for students learning evaluation: the first one is to evaluate the accuracy, which is to accurately reflect the students' learning conditions; the second one is a comprehensive evaluation, to reflect the learning status of students from many aspects, the third one is the evaluation incentive, to be able to promote students' learning to make further efforts.

\subsection{Learning Evaluation Principle}

During the students' learning process, teachers gives the give evaluation and incentive for students learning behavior, it can stimulate students' interest in learning, to enable students to produce the driving force for active learning, strengthen the awareness of active learning, and there must be based on certain principles. In education research scholars' opinion, study and evaluation of the real purpose is to emancipate learners (students), and let the students learn happy; to create learners, let students learn how to autonomous learn; to promote learner, let students all-round development; to stimulate learners, let students experience the joy of success; to stimulate teachers, let teachers feel the happiness brought by teaching [10].

As a complete subversion of the traditional model, new cyberspace support mode is based on the principle of traditional teaching evaluation, which follows the main principle, incentive principle, process principle and the development principle. The subjectivity principle is that the student is the main body of the teaching. Therefore, studying evaluation should be designed closely around the students; the incentive principle is through the evaluation, let the students feel that learning is happy, and make students personal experience to the success of heartfelt joy; process principle is that the teaching requirements of each process should have the evaluation, teaching process is the evaluation process; development principle is that the student obtains result and reflection of problems, attitude and strategy are evaluated as well.

\subsection{Learning Evaluation Function}

With the application of internet technology into the teaching, the diversification function of evaluation is particularly prominent. The study of American educational research is divided into three types, namely, diagnostic evaluation, formative evaluation and summary evaluation. And based on this, five functions of diagnosis, feedback, orientation, identification and education of learning evaluation are proposed. Diagnostic function is through a variety of tests to understand and grasp students' knowledge level and problems existed in the learning; feedback function is a test evaluation (positive or negative); orientation function is that the learning time and power are allocated by evaluating standard and test content guide; identification function is the identification of the learning results evaluation; education function is that a variety of evaluations during the process of teaching is a kind of educational activities [11].

The development function of learning evaluation is to paid more attention based on the continuous observation and record of the whole process of students learning, and then reflects and give the comprehensive evaluation process. The main purpose of development evaluation is to clarify the problems existing in the operation of teaching activities and the direction of improvement, timely revise or adjust the learning program to obtain more ideal learning effect, so that students change from the passive acceptance of the evaluation to the subject of assessment and active participants of evaluation.

\subsection{Learning Evaluation Method}

The cyber learning evaluation method under the support of the space should be more rich and scientific. It is including the performance evaluation, self evaluation, learning contract evaluation and tracking files evaluation, et al.

Performance evaluation is based on the criticism of traditional test; self evaluation is that the rated objects (students) are evaluated according to the evaluation standard of self evaluation and judgment; learning contract evaluation is using contract learning on students' learning process; and tracking files evaluation is a comprehensive assessment of the individual students throughout the learning files automatically are generated at the end of the course.

\subsection{Evaluation Index Analysis}

Evaluation index is an important basis to make scientific, reasonable, fair and impartial evaluation. In view of the characteristics of learning environment supported by cyber learning space, three levels of the evaluation index are designed according to the weight $[12,13]$.

First level indexes are including final test and mid-term test of online course supported by test questions library. Second level indexes including unit test, the teaching content is divided into a plurality of units, at the end of each teaching unit, students must complete the corresponding unit refers to a constant level of random testing, each test scores are recorded by system; third level indexes are including online course independent training and online tutorial interaction. According 
to their own learning needs, choose the test sites, the difficulty and the quantity for autonomous learning training, online discussion and tutoring are real-time recorded. Finally, according to the statistical results and weights, the total evaluation results of the course are generated $[14,15,16]$.

At the end of the course, the teacher can further carry on the performance management and analysis, and examination management and analysis. Furthermore, collected data is taken as the basis, and the evaluation index is taken as the evidence. By using hierarchical analysis method (AHP), cluster analysis method, the main factor analysis method and modeling technology, the qualitative research and development research for the learning evaluation of cyber learning support are carried out.

\section{Practice of Learning Evaluation System Under Cyber Learning Space}

For new subject of internet learning evaluation under internet environment, in order to achieve the accuracy of learning evaluation, the comparative analysis is carried out with traditional teaching mode, the evaluation of learning. The principle, function, method and index of learning evaluation are gradually clarified, based on the cyber learning space environment.

How to grasp and track students' learning links under the Internet environment, and how to analyze massive data in each link, a perfect index system evaluation model is established for data acquisition, data analysis and data processing method.

During the process of research, we absorb cross professional research members to join into the team, through the depth of work summary, more team members are trained and improved, the team's research ability has been improved rapidly, the research results are actively promoting application and efforts in cyber learning space to support the learning evaluation system research and application in the leading role.

\section{Conclusion}

In the internet era, cyber learning space is more and more getting into the students' learning process, perhaps it may replace the traditional classroom teaching mode in the near future. The learning evaluation system established in this paper combines the function of traditional learning evaluation, and has the characteristics of cyber learning space environment, so it can be said to be a very realistic system, and with wide application prospect.

Of course, many scholars in this respect also made a lot of fruitful work and achieved gratifying results, from different perspectives. Although this paper established the evaluation system of the cyber learning space, how to keep up with the rapid development of the internet, is the future research topics. So it is also need to improve and perfect constantly. Furthermore, it is a very notable to study the evaluation system of teachers under the environment of cyber learning space.

\section{Acknowledgement}

The authors thank for Professor Li Jihuai and Professor Fan Zengguang, who do a lots of beneficial work for finishing this paper. The authors here would like to thank colleagues for their support of this research work.

\section{References}

[1] W. Gibson, Neuromancer, London: Voyager, 1995.

[2] A. Lenhart. Teens, Social Media \& Technology Overview 2015. http://www.pewinternet.org/2015/04/09/teens-socialmedia-tec hnology-2015/, 2016-2-19.

[3] Xinhuanet. China campus weibo development report (2015). http://news.xinhuanet.com/newmedia/2015-08/20/c_13453470 2.htm, 2016-2-19.

[4] M. Weller, Virtual learning environments: Using, choosing and developing your VLE. London: Routledge, 2007.

[5] California Education Code Section, http://www.cde.ca.gov $/ \mathrm{ta} / \mathrm{tg} / \mathrm{ca} /, 2016-4-7$.

[6] Z. T. Zhu, J. Q. Guan, "Everyone on the cyber learning space construction framework," China Educational Technology, 2013(10): pp. 1-7.

[7] P. Wang, "Analyses the education informatization development process," China Educational Technology \& Equipment, 2013(27): pp. 19-20.

[8] S. C. Zhang, M. K. Liang, G. L. Huang, et al., "The application of formative evaluation in the regional anatomy teaching," Journal of Guangxi University of Chinese Medicine, 2015, vol. 18, pp. 120-122.

[9] Y. H. Wu, "Knowledge management in the application of the modern open and distance education courses," Journal of Changchun Education Institute, 2015, vol. 31, pp. 4-6.

[10] Z. Han, D. Y. Qiu, "The importance and suggestions for the construction of university cyber learning space under the background of Internet+ education," Software Guide, 2015(11), pp. 18-19.

[11] Y. L. Huang, D. Q. Zhu, "The complexity and situational coupling: the new orientation of cyberspace learning evaluation and its path to explore," e-Education Research, 2013(7), pp. 47-52.

[12] Z. Y. Chang, T. Dong, "The design and implementation of the evaluation of web-based learning," Journal of Jiangsu Radio \& Television University, 2006(1), pp. 26-29.

[13] M. Cao, "Requirements and implementation of learning assessments in networked study," Distance Education in China, 2002(1), pp. 45-48.

[14] H. Y. Liu, Innovation in the depth integration of learning space and teaching," The Chinese Journal of ICT in Education, 2013(14), pp. 62.

[15] Y. B. Li, Y. Y. Wang, J. Z. Ma, X. L. Wu, B. B. Zhang, "Research on the teacher evaluation index system of cyber learning space," e-Education Research, 2015(6), pp. 100-106.

[16] L. Wang. "Research on learning evaluation based on cyber learning platform," The Chinese Journal of ICT in Education, 2010(14), pp. 45-47. 